\title{
Working Memory and the Suppression of Reflexive Saccades
}

\section{Citation}

Mitchell, Jason Paul, C. Neil Macrae, and lain D. Gilchrist. 2002. Working memory and the suppression of reflexive saccades. Journal of Cognitive Neuroscience 14(1): 95-103.

\section{Published Version}

doi:10.1162/089892902317205357

\section{Permanent link}

http://nrs.harvard.edu/urn-3:HUL.InstRepos:4725202

\section{Terms of Use}

This article was downloaded from Harvard University's DASH repository, and is made available under the terms and conditions applicable to Other Posted Material, as set forth at http:// nrs.harvard.edu/urn-3:HUL.InstRepos:dash.current.terms-of-use\#LAA

\section{Share Your Story}

The Harvard community has made this article openly available.

Please share how this access benefits you. Submit a story.

Accessibility 


\title{
Working Memory and the Suppression of Reflexive Saccades
}

\author{
Jason P. Mitchell ${ }^{1}$, C. Neil Macrae ${ }^{2}$, and Iain D. Gilchrist ${ }^{3}$
}

\begin{abstract}
Conscious behavioral intentions can frequently fail under conditions of attentional depletion. In attempting to trace the cognitive origin of this effect, we hypothesized that failures of action control-specifically, oculomotor movement-can result from the imposition of fronto-executive load. To evaluate this prediction, participants performed an antisaccade task while simultaneously completing a workingmemory task that is known to make variable demands on prefrontal processes ( $n$-back task, see Jonides et al., 1997).
\end{abstract}

\section{INTRODUCTION}

Action slips serve as timely reminders of the power of unconscious (i.e., automatic) behavioral forces (James, 1890; Freud, 1901/1966). Notwithstanding the possession of a conscious intention to take a novel route to work, one may nevertheless find oneself following the regular path to the office. Similarly, attempts to call a new partner may flounder as one finds oneself dialing the apartment of his or her immediate predecessor. In tracing the cognitive origin of behavioral lapses such as these, researchers have noted that action slips commonly arise when people's current objectives and established behavioral propensities are in conflict or opposition (Reason, 1979). As James (1890) memorably observed, "Persons in going to their bedroom to dress for dinner have been known to take off one garment after another and finally to get into bed, merely because that was the habitual issue of the first few movements when performed at a later hour"' (p. 155). Inspection of the available literature on this topic reveals that action slips are most likely to occur when the mind is otherwise engaged in some concurrent mental activity, such as daydreaming, rumination, or listening to the radio (e.g., Norman, 1981; Reason, 1979). Put simply, behavioral lapses are the result of a preoccupied or distracted mind.

That distraction can prompt the failure of conscious behavioral intentions has been demonstrated by Wegner and his colleagues in their influential research on mental control (see Wegner, 1994). The empirical findings tell a

\footnotetext{
${ }^{1}$ Harvard University, ${ }^{2}$ Dartmouth College, ${ }^{3}$ University of Bristol
}

The results of two experiments are reported. As expected, antisaccade error rates were increased in accordance with the fronto-executive demands of the $n$-back task (Experiment 1). In addition, the debilitating effects of workingmemory load were restricted to the inhibitory component of the antisaccade task (Experiment 2). These findings corroborate the view that working memory operations play a critical role in the suppression of prepotent behavioral responses. compelling tale. Under conditions of attentional depletion, not only does behavioral self-regulation fail, but perceivers are propelled into performing actions they are trying to avoid. For example, instructed not to blast a golf putt past the cup, perceivers proceed to do just that-sending the ball on average $20 \mathrm{~cm}$ past its intended target, but only under conditions of resource depletion. Similarly, participants swing a handheld pendulum more frequently along a forbidden axis when under cognitive load (Wegner, Ansfield, \& Pillof, 1998). But why exactly do action slips emerge in attentionally demanding task environments? In particular, what is it about resource depletion and the dynamics of action control that prompts conscious intentions to fail and perceivers to produce prepotent behavioral responses (Norman, 1981; Reason, 1979; James, 1890)?

According to conventional wisdom, fronto-executive operations are believed to play a fundamental role in the regulation of thought and action. Norman and Shallice (1986), for example, have argued that action is controlled either by preexisting behavioral schemas that guide response selection in familiar settings, or else by a frontally mediated Supervisory Attentional System (SAS) that guides the elicitation of action in novel, surprising, or dangerous task environments (see also Baddeley, 1996). With regard to the higher-order control of action, one critical function of the SAS is to inhibit the execution of overlearned responses in contextually inappropriate settings (Damasio, 1994; Shallice, 1988; Baddeley, 1986, 1996; Luria, 1966). Thus, the appearance of a green light would not prompt one to drive across an intersection, if a pedestrian was still standing 
in the middle of the road. That executive operations regulate the elicitation of habitual or overlearned responses in this manner is apparent from the behavior of individuals who have suffered damage to the prefrontal cortex (PFC; Kimberg \& Farah, 1993; Fuster, 1989; Shallice, 1988; Lhermitte, 1983). On a range of tasks that are sensitive to frontal functioning (e.g., Wisconsin Card Sort Task, Tower of Hanoi Task, and Stroop Task) these persons typically demonstrate an inability to suppress inappropriate behaviors in favor of strategies that would lead to correct responding (see Shallice, 1988). In other words, executive dysfunction impairs the mind's ability to replace prepotent responses with goal-relevant behavioral responses (Shallice, 1988; Norman \& Shallice, 1986).

Interestingly, it is not only frontal patients who may display an inability to inhibit habitual responses. It should be possible, at least in principle, to induce similar effects (albeit temporarily) in healthy adults under specific dual-task conditions (Stuyven, Van der Goten, Vandierendonck, Claeys, \& Crevits, 2000; Roberts, Hager, \& Heron, 1994). All that may be needed to realize this objective is: (i) an experimental task in which people's processing goals and prepotent behavioral tendencies are in opposition; and (ii) a concurrent activity that impairs the efficiency of fronto-executive operations. One task that quite clearly satisfies the former requirement is the antisaccade task (Hallet, 1978). Saccadic eye movements to visual stimuli can be generated either reflexively or intentionally (Findlay, 1981). Reflexive saccades occur rapidly and are initiated in response to abrupt visual onsets. Intentional saccades, in contrast, take longer to execute and are triggered by people's processing goals. In the antisaccade task (Hallet, 1978), a peripheral stimulus appears on the screen while the participant is fixating on a central cue. The participant's task is simply to suppress the reflexive (i.e., prepotent) response toward the stimulus and to make an intentional saccade in the opposite direction. Performance is then compared with a prosaccade condition in which the participant's instruction is to look at the peripheral stimulus. Generally speaking, antisaccades take longer to initiate than prosaccades and saccade direction errors (i.e., action slips) are more common in the anti- than the prosaccade condition (Everling \& Fischer, 1998).

Of relevance to the present investigation, two neuroanatomical systems are acknowledged to play a prominent role in the control of saccadic eye movements (see Everling \& Fischer, 1998). While reflexive saccades are initiated primarily by activity in the superior colliculus (SC), a structure in the midbrain, antisaccade generation critically involves areas of the PFC. Evidence to corroborate the involvement of fronto-executive operations in the suppression of reflexive saccades comes from a variety of sources. Guitton, Büchtel, and Douglas (1985), for example, contrasted the antisaccade per- formance of patients with damage to the prefrontal or temporal cortex. The results revealed that only frontal patients showed elevated error rates on the task, patients with temporal lobe lesions were not impaired (Paus et al., 1991). Similarly, Pierrot-Deseilligny, Rivaud, Gaymard, and Agid (1991) compared the antisaccade performance of patients with lesions in different regions of the frontal lobes. Whereas damage to PFC resulted in an antisaccade deficit (Fukushima et al., 1988), impairment did not result for patients whose lesions were restricted to either the frontal or supplementary eye fields (FEF or SEF). Another strand of evidence comes from the neuroimaging literature. Although imaging studies have yet to provide a fully coherent picture, what is apparent is that dorsolateral prefrontal cortex (DLPFC) appears to play a prominent role in the generation of antisaccades (Doricchi et al., 1997; Sweeney, Mintun, \& Kwee, 1996). Finally, increased antisaccade error rates have also been observed in older adults, a group that is believed to display impairments in the efficiency of executive functioning (Butler, Zacks, \& Henderson, 1999). Taken together, these findings confirm the involvement of fronto-executive operations in the suppression of reflexive saccades. When these processes are compromised through cortical insult or the cognitive changes associated with aging, elevated error rates are observed on the antisaccade task.

But is it also possible to elicit antisaccade errors in healthy younger adults under conditions of experimentally induced fronto-executive load? Recent research suggests that indeed it may, with working memory serving a critical function in the suppression of reflexive eye movements (Stuyven et al., 2000; Roberts et al., 1994). A common component of tasks that are known to be sensitive to frontal functioning, such as the antisaccade task, is that they involve the suppression of a prepotent or overlearned response (i.e., a reflexive saccade). To inhibit this response, of course, participants must be able to maintain the relevant task instructions in memory (i.e., 'look away from the peripheral stimulus'), otherwise errors (reflexive saccades) are likely to occur (see also Kimberg \& Farah, 1993; Cohen \& Servan-Schreiber, 1992). Supporting this viewpoint, Roberts et al. (1994) demonstrated an increase in antisaccade error rates under dual-task conditions in which participants were required to perform a demanding working-memory task (i.e., mental arithmetic). Importantly, a less demanding concurrent activity (i.e., digit verbalization) failed to impair the suppression of reflexive saccades, prompting Roberts et al. to conclude that, "increasing concurrent working-memory load increases reflexive responding" (p. 391). But why exactly does working-memory load moderate performance on the antisaccade task? What is it about certain concurrent tasks that prompts conscious intentions to fail and reflexive responding to ensue? 
Following others, our intuition is that working-memory processes-particularly, executive operations-play a critical role in the inhibition of prepotent behavioral responses (Bjorklund \& Harnishfeger, 1995; GoldmanRakic, 1995; Harnishfeger \& Bjorklund, 1993; Kimberg \& Farah, 1993; Cohen \& Servan-Schreiber, 1992; Dehaene \& Changeux, 1991; Fuster, 1989; Levine \& Prueitt, 1989; Norman \& Shallice, 1986). As such, only when concurrent tasks make notable demands on the efficiency of prefrontal processes may performance on the antisaccade task be impaired. Although previous research has alluded to this possibility (Roberts et al., 1994), the reported results provide only indirect evidence for this viewpoint as compelling neuroimaging data are not yet available for these specific working memory task. As a result, it is unclear the extent to which fronto-executive operations were involved in the working-memory tasks that participants were required to perform (Stuyven et al., 2000; Roberts et al., 1994). Consequently, although the results are suggestive, it is not possible to conclude that reflexive responding is exacerbated under conditions of fronto-executive load. What is apparent is that dual tasks that make minimal or no demands on executive operations do not promote reflexive responding (Stuyven et al., 2000; Roberts et al., 1994). To provide unequivocal evidence for such a link, one requires a working memory task that makes known (and variable) demands on prefrontal operations.

One task that offers such a possibility is the $n$-back task (Jonides et al., 1997; Smith \& Jonides, 1997). In this task, participants are presented with a series of letters (or numbers) and for each one they have to decide whether it matches the item that preceded it by $n$ places in the sequence. For example, a 1-back task requires participants to judge whether the current letter is the same as the preceding item in the sequence. Some $n$-back paradigms also include a 0 -back condition in which participants judge whether the current letter is the same as a target letter that was specified previously by the experimenter. What is theoretically noteworthy about this monitoring task is that neuroimaging studies (i.e., PET) have confirmed that as the number of $n$ increases from 0 to 1 to 2, regional cerebral blood flow (rCBF) in a number of brain regions increases (or decreases) in a linear fashion (Jonides et al., 1997). Indeed, this is the case for a number of frontal areas. Critically, however, rCBF change in DLPFC does not conform to this linear pattern. Instead, relative to a control condition, rCBF increases of $1.39 \%$ and $1.34 \%$ are observed during the 0-back and 1-back tasks, respectively; but an increase of $3.44 \%$ is observed in the 2-back task. This confirms, therefore, that the 2-back task makes different demands on functional subsystems within the frontal lobes (Jonides et al., 1997). In particular, systems anterior to the FEF are differentially affected by working-memory load.

These neuroimaging results are valuable as they enable one to make precise predictions about the effects that may be observed when a saccadic eye movement and $n$-back task are performed simultaneously. As prosaccade performance does not critically entail frontal operations (Everling \& Fischer, 1998), the concurrent performance of an $n$-back task (0-, 1-, or 2-back) should not disrupt people's ability to saccade in the direction of a peripheral target. Quite different effects should emerge, however, when one considers performance on an antisaccade task. Specifically, whereas 0- and 1-back tasks should impair performance to a similar (and marginal) degree, a 2-back task should have a more disruptive impact on people's ability to suppress reflexive saccades, essentially because it makes greater demands on fronto-executive operations, particularly functions localized in the DLPFC (Jonides et al., 1997; Smith \& Jonides, 1997). Thus, despite the conscious intention to look away from a peripherally presented stimulus, under conditions of experimentally induced fronto-executive load (i.e., 2-back task), participants may find it notoriously difficult to ignore the said item. We investigated this prediction in the two experiments reported herein. The purpose of the present research was twofold. First, to establish the effects of workingmemory load on the elicitation of reflexive saccades (i.e., Experiment 1). Second, to identify the components of oculomotor control that are impeded under conditions of fronto-executive load (i.e., Experiment 2).

\section{RESULTS}

\section{Experiment 1}

In our first experiment, participants performed blocks of antisaccade and prosaccade trials while simultaneously completing an $n$-back task that makes variable demands on fronto-executive operations (see Jonides et al., 1997). The results are summarized below.

\section{Saccade Direction Accuracy}

Table 1 presents the eye movement data. We did not analyze trials in which: (i) participants were not looking at the fixation circle when the peripheral stimulus appeared; (ii) the latency of the initial saccade was less than $75 \mathrm{msec}$ (i.e., anticipatory saccades); (iii) the latency of the response was greater than 3 standard deviations from the mean (i.e., outliers); and (iv) eye movement was less than $1^{\circ}$ in the horizontal plane. Application of these criteria eliminated $7.7 \%$ of the data. Errors were trials on which the participant's first saccade was in the wrong direction and error rates were calculated as the proportion of correct saccades given the total number of trials in the analysis (per participant). These data were then submitted to a 2 (condition: prosaccade or antisaccade) $\times 4$ (concurrent task: none or 0-, 1-, or 2-back) repeated measures analysis of variance (ANOVA). This revealed main effects of both condition $[F(1,15)=10.44, p<.01]$ and concurrent task 
Table 1. Saccade and $n$-Back Performance as a Function of Working-Memory Load (Experiment 1)

\begin{tabular}{|c|c|c|c|c|}
\hline & \multicolumn{4}{|c|}{ Memory Load } \\
\hline & Control & O-Back & 1-Back & 2-Back \\
\hline \multicolumn{5}{|c|}{ Proportion correct } \\
\hline \multicolumn{5}{|c|}{ Saccade direction } \\
\hline prosaccade & .984 & .984 & .966 & .972 \\
\hline antisaccade & .939 & .913 & .898 & .866 \\
\hline \multicolumn{5}{|l|}{$n$-back task } \\
\hline prosaccade & - & .950 & .969 & .920 \\
\hline antisaccade & - & .958 & .944 & .907 \\
\hline \multicolumn{5}{|c|}{ Correct trial response latency (msec) } \\
\hline \multicolumn{5}{|c|}{ Saccade direction } \\
\hline prosaccade & 162 & 163 & 158 & 170 \\
\hline antisaccade & 229 & 214 & 218 & 211 \\
\hline \multicolumn{5}{|l|}{$n$-back task } \\
\hline prosaccade & - & 804 & 859 & 913 \\
\hline antisaccade & - & 755 & 797 & 830 \\
\hline
\end{tabular}

$[F(3,45)=6.64, p<.001]$ on the accuracy of participants' saccades. As expected, however, these effects were qualified by a Condition $\times$ Concurrent Task interaction $[F(3,45)=2.90, p<.05$; see Table 1]. Simple effects analysis confirmed that whereas prosaccades were not affected by the imposition of a concurrent task $[(F(3,45)=2.05, n s]$, antisaccade performance was substantially impaired under dual-task conditions $[F(3$, $45)=5.40, p<.01]$. Critically, post hoc comparisons revealed that performance on the antisaccade task differed only between the 1- and 2-back conditions $(p<.04)$. There was no difference in performance between the 0 - and 1-back conditions and only a marginally significant decrement in performance between the control and 0-back conditions $(p<.09)$. Interestingly, these results parallel the rCBF increases $(1.39 \%, 1.34 \%$, and $3.44 \%$ rCBF change in the 0 -, 1-, and 2-back tasks, respectively) that have been observed in the DLPFC while participants perform the $n$-back task (Jonides et al., 1997; Smith \& Jonides, 1997). As one would expect from the neuroimaging data (Jonides et al., 1997), antisaccade performance was most impaired in the 2back condition and differences did not emerge between the 0 - and 1-back conditions.

\section{Latency of Correct Saccades}

A 2 (condition: prosaccade or antisaccade) $\times 4$ (concurrent task: none or 0-, 1-, or 2-back) repeated meas- ures ANOVA was undertaken on the data. This revealed a main effect of condition on participants' latencies $[F(1,15)=94.25, p<.001]$. Antisaccade latencies $(M=218 \mathrm{msec})$ were slower than prosaccade latencies $(M=163 \mathrm{msec})$. The analysis also revealed a Condition $\times$ Concurrent Task interaction $[F(3,45)=4.19, p<.01]$. Additional analyses confirmed an effect of concurrent task on prosaccade $[F(3,45)=3.06, p<.04]$, but not antisaccade latencies. Inspection of the prosaccade treatment means revealed that response latencies were fastest in the 1-back than the other three conditions. Importantly, there was no systematic increase in latency across conditions consistent with a speed-accuracy trade off.

\section{n-Back Performance}

Table 1 presents the $n$-back data. Errors comprised trials on which participants made an incorrect response or trials on which no response was given. The data were submitted to a 2 (condition: prosaccade or antisaccade) $\times 4$ (concurrent task: 0-back or 1-back or 2-back) repeated measures ANOVA. This revealed only a main effect of concurrent task on participants' $n$-back performance $[F(2,30)=11.35$, $p<.001]$. As expected, performance on the $n$-back task was best in the 0-back condition and worst in the 2-back condition. Post hoc comparisons confirmed that while performance in the 0 - and 1-back conditions did not differ significantly, reliable differences emerged between the 1- and 2-back conditions ( $p<$ .001). Critically, the failure to obtain a Condition $\times$ Concurrent Task interaction indicated that, regardless of the direction of saccadic eye movements, the $n$ back task imposed equivalent cognitive demands on participants' processing capacity. A 2 (condition: prosaccade or antisaccade) $\times 4$ (concurrent task: 0-, 1-, or 2-back) repeated measures ANOVA was undertaken on the latencies of correct $n$-back trials. This revealed main effects of condition $[F(1,15)=5.21, p<.04]$ and concurrent task $[F(2,30)=5.37, p<.02]$ on participants' response times. Latencies were slower in the antisaccade than the prosaccade condition and response times were greater as the demands of the $n$-back task increased. There was no evidence of a Condition $\times$ Concurrent Task interaction on participants' response latencies $[F(2,30)<1, n s]$.

\section{Discussion}

These findings provide preliminary support for our predictions. As expected, the error rate in the antisaccade task was elevated under dual-task conditions that are known to make significant demands on fronto-executive operations (Jonides et al., 1997; Smith \& Jonides, 1997). Thus, it is not only frontal patients or older adults who may be unable to suppress 
reflexive saccades (Butler et al., 1999; Guitton et al., 1985), similar effects can be observed in healthy young adults under conditions of experimentally induced executive load. Without the flexibility that fronto-executive functioning affords (Norman \& Shallice, 1986), participants found themselves looking at a stimulus they were attempting to ignore. Of course, to perform the antisaccade task successfully, participants must be able to do at least two things (Everling \& Fischer, 1998): (i) inhibit the generation of a reflexive saccade to the peripheral stimulus (i.e., inhibitory component); and (ii) initiate a voluntary eye movement in the opposite direction (i.e., volitional component). What is unclear from the results of Experiment 1, however, is the extent to which working-memory load impairs these different components of the antisaccade task (Stuyven et al., 2000; Roberts et al., 1994). For example, is it the case that the effects of working-memory load are restricted to the inhibitory component of the antisaccade task (Guitton et al., 1985), or do they extend instead to both the suppression of reflexive saccades and the generation of volitional eye movements? Through the addition of a no-saccade condition to the standard antisaccade task (Walker, Husain, Hodgson, Harrison, \& Kennard, 1998), we investigated this important issue in our second experiment. In the no-saccade condition participants are simply required to maintain fixation. Like the antisaccade task, such a task required the inhibition of the reflexive saccade. But, unlike the antisaccade task, it does not require the generation of a voluntary eye movement.

\section{Experiment 2}

In our second experiment, participants completed blocks of antisaccade and no-saccade trials while simultaneously performing various levels of the $n$-back task. The results are summarized below.

\section{Saccade Direction Accuracy}

Table 2 presents the eye movement data. We did not analyze trials in which the latency of the initial saccade was less than 75 msec (i.e., anticipatory saccades) or the latency of the response was greater than 3 standard deviations from the mean (i.e., outliers). Application of these criteria eliminated $1.1 \%$ of the data. For antisaccade blocks, errors were trials on which the participant's first saccade was in a direction other than directly away from the peripheral target. For no-saccade blocks, errors were trials on which the participant made an eye movement greater than $1^{\circ}$ in any direction. Error rates were calculated as the proportion of correct saccades given the total number of trials in the analysis (per participant). These data were then submitted to a 2 (condition: no-saccade or antisaccade) $\times 3$ (concurrent task: 0-, 1-, or 2-back) repeated measures ANOVA. This revealed
Table 2. Saccade and $n$-Back Performance as a Function of Working-Memory Load (Experiment 2)

\begin{tabular}{cccc}
\hline & \multicolumn{3}{c}{ Memory Load } \\
\cline { 2 - 4 } & O-Back & 1-Back & 2-Back \\
\hline Proportion correct & & & \\
Saccade direction & & & .840 \\
no-saccade & .887 & .873 & .638 \\
antisaccade & .706 & .710 & \\
$n$-back task & & & .904 \\
no-saccade & .949 & .920 & .826 \\
antisaccade & .931 & .905 &
\end{tabular}

Correct trial response latency (msec)

Saccade direction

\begin{tabular}{cccc} 
no-saccade & - & - & - \\
antisaccade & 244 & 262 & 256 \\
$n$-back task & & & \\
no-saccade & 827 & 917 & 1005 \\
antisaccade & 1063 & 1141 & 1194 \\
\hline
\end{tabular}

main effects of both condition $[F(1,17)=9.78, p<$ $.01]$ and concurrent task $[F(2,34)=5.36, p<.01]$ on the accuracy of participants' saccades. Importantly, however, the analysis failed to reveal a significant Condition $\times$ Concurrent Task interaction $[F(2,34)=1.20, n s]$. Post hoc comparisons revealed that task performance differed only between the 1- and 2-back conditions ( $p<$ $.04)$. There was no difference in performance between the 0 - and 1-back conditions. In addition, performance was better in the no-saccade than the antisaccade task. Thus, as the $n$-back task exerted equivalent effects on both the no-saccade and antisaccade tasks, it would appear that executive load impaired only the suppression of reflexive saccades, no additional disruptive effects were apparent on the initiation of volitional eye movements.

\section{Latency of Correct Antisaccades}

A single factor (concurrent task: 0-, 1-, or 2-back) repeated measures ANOVA was undertaken on the latency of participants' antisaccades (no such analysis was possible for no-saccade blocks, since participants were told not to move their eyes during these trials). This analysis revealed that antisaccades were reliably slower across the $n$-back conditions $F(2,34)=3.50$, $p<.05]$. Paralleling the pattern of participants' errors, post hoc comparisons confirmed that antisaccade latencies differed between 0 - and 1-back tasks $(p<.03)$ and between 0 - and 2-back tasks $(p<.05)$. 


\section{n-Back Performance}

Table 2 presents the $n$-back data. Errors comprised trials on which participants made an incorrect response or trials on which no response was given. The data were submitted to a 2 (condition: no-saccade or antisaccade) $\times 3$ (concurrent task: 0-, 1-, or 2-back) repeated measures ANOVA. This revealed only main effects of condition $[F(1,17)=4.39, p<.05]$ and concurrent task $[F(2,34)=6.71, p<.01]$ on participants' $n$-back performance. As expected, performance on the $n$-back task was best in the 0-back condition and worst in the 2-back condition. Post hoc comparisons confirmed that while performance in the 0 - and 1-back conditions did not differ significantly, reliable differences emerged between the 1 - and 2-back conditions $(p<.03)$. In addition, performance was better in the no-saccade than the antisaccade task. This latter finding is important as it confirms that it is not simply combined task difficulty that prompts the elicitation of reflexive eye movements in the antisaccade task. In a less demanding task context in which $n$-back performance is high (i.e., no-saccade task), an identical pattern of effects is observed. A 2 (condition: no-saccade or antisaccade) $\times 3$ (concurrent task: 0-, 1-, or 2-back) repeated measures ANOVA was also undertaken on the latencies of correct $n$-back trials. This revealed main effects of condition $[F(1,17)=26.43$, $p<.001]$ and concurrent task $[F(2,34)=12.92, p<$ .001] on participants' response times. Latencies were slower in the antisaccade than the no-saccade condition and response times were greater as the demands of the $n$-back task increased. There was no evidence of a Condition $\times$ Concurrent Task interaction on participants' response latencies $[F(2,34)<1, n s]$.

\section{Discussion}

Replicating the results of Experiment 1, the present findings revealed an increase in reflexive responding under conditions of fronto-executive load. In addition, however, the observed performance decrement in the 2-back condition was traced to the debilitating effect of working-memory load on the inhibitory component of the antisaccade task (cf. Stuyven et al., 2000; Roberts et al., 1994). Results in the no-saccade condition displayed the same general pattern as the $\mathrm{rCBF}$ increases that have been observed in the DLPFC when participants perform the $n$-back task (Jonides et al., 1997; Smith \& Jonides, 1997). Specifically, reflexive responding was most pronounced in the 2-back condition and differences did not emerge between the 0 - and 1-back conditions. As the pattern of impairment was identical in the antisaccade task, this suggests that working-memory load exerts quite specific effects on the control of saccadic eye movements. That is, whereas executive load impairs people's ability to suppress reflexive saccades, it has little additional disruptive impact on their capacity to generate volitional eye movements. In other words, fronto-executive operations appear to play a critical role in the inhibitory aspects of action control, particularly the suppression of prepotent or overlearned responses (see Bjorklund \& Harnishfeger, 1995; Shallice, 1988; Norman \& Shallice, 1986).

\section{GENERAL DISCUSSION}

Extending previous work on this topic, the present research provided direct evidence for a relationship between working-memory processes and the regulation of saccadic eye movements (Stuyven et al., 2000; Roberts et al., 1994). On the basis of existing neuroimaging data (Jonides et al., 1997), we anticipated that reflexive responding would be increased under dual-task conditions that make notable demands on fronto-executive operations (i.e., 2-back condition). Not only did our results corroborate this prediction, but they also revealed that executive load impairs the inhibitory component of the antisaccade task (Everling \& Fischer, 1998). In this way, the findings are consistent with the view that the DLPFC plays a critical role in the generation of inhibitory responses. Indeed, inhibitory control may be a primary function of specific regions of $\mathrm{PFC}$ (Goldman-Rakic, 1995; Cohen \& Servan-Schreiber, 1992). But why exactly does fronto-executive load promote the elicitation of prepotent eye movements? How does working memory interact with the suppression of reflexive saccades?

According to Hallett (1978), reflexive saccades are suppressed when frontal processes send a stop or cancellation signal to the SC. The timing of this signal, however, is crucial. If its generation is delayed beyond a critical point, reflexive responding ensues. Adopting this viewpoint, Guitton et al. (1985) have suggested that frontal patients show elevated error rates on the antisaccade task because of the time it takes them to generate the necessary cancellation signals. In this respect, it is likely that operations shared by both working memory and stop signal generation are implicated in the errant eye movements that these patients produce. Funahashi, Bruce, and Goldman-Rakic (1993), for example, have shown that neurons in monkey DLPFC are involved not only in the maintenance of the spatial location of a target in memory, but also in the suppression of a response toward that item. As such, if response inhibition is a basic function of working memory, fronto-executive operations must surely be involved in the generation of cancellation signals in the antisaccade task (Guiton et al., 1985; Hallett, 1978). This viewpoint gains additional support when one considers the direct and indirect projections the SC receives from frontal areas (Goldman-Rakic, 1995; Fuster, 1989). When operating in an unimpeded manner, executive processes send the necessary cancellation signals to the SC during the antisaccade task. Under conditions of fronto-executive load (i.e., 2-back task), however, the generation of these signals is 
impeded and reflexive saccades are initiated. In this way, then, working-memory processes and inhibitory operations work in concert to regulate the expression of prepotent behavioral responses (see Walker et al., 1998).

Arguably the basis of human achievement resides in people's ability to withhold inappropriate responses, be they sexual, emotional, or aggressive in nature. As Bjorklund and Harnishfeger (1995) have noted, "inhibition of prepotent, emotional, or learned responses seems to be necessary for effective life in a complex social primate group" (p. 166). In the context of an oculomotor task, the present findings revealed how fronto-executive operations provide the flexibility that an adaptive behavioral repertoire requires. Through the inhibition of a reflexive visual response, perceivers were able to act in accordance with their conscious behavioral intentions. Although restricted to the regulation of saccadic eye movements, it is likely that the present findings would extend to any task domain in which perceivers' current goals and prepotent behavioral tendencies are in conflict or opposition (see also Jonides, Smith, Marscuetz, Koeppe, \& Reuter-Lorenz, 1998). In other words, regardless of the task context, frontoexecutive load should promote behavioral rigidity and reflexive responding (see Shallice, 1988; Norman \& Shallice, 1986). For example, on entering the bedroom in a distracted state of mind, one may clamber into bed rather than realize one's intended objective of dressing for dinner (James, 1890), if executive operations are required for the planning, monitoring, or maintenance of some concurrent mental activity. The failure of conscious behavioral intentions, moreover, need not be triggered by cortical insult, mental illness, or the neurological changes associated with aging (Everling \& Fischer, 1998). Instead, action control can fail in healthy younger adults under quite specific conditions-notably dual-task settings that make consequential demands on specific working-memory operations (Jonides et al., 1997; Smith \& Jonides, 1997). Without the flexibility that fronto-executive functioning affords, reflexive (i.e., prepotent, overlearned) responses are likely to emerge.

\section{METHODS}

\section{Experiment 1}

\section{Participants and Design}

Sixteen students and research staff at the University of Bristol participated in the experiment. The experiment had a 2 (condition: prosaccade or antisaccade) $\times 4$ (concurrent task: none or 0-, 1-, or 2-back) repeated measures design.

\section{Procedure and Stimulus Materials}

Eye movements were recorded with a SMI video-based eyetracker controlled by an IBM-compatible microcom- puter. The eyetracker sampled eye positions at a frequency of $250 \mathrm{~Hz}$, allowing saccade latencies to be calculated with a temporal resolution of $4 \mathrm{msec}$. Spatial calibration was carried out at the beginning of each block of trials using a standard 9-point calibration sequence. The operational spatial resolution of the apparatus was $0.3^{\circ}$ of visual angle. Stimuli were displayed on a 17-in. color VDU monitor and participants' head movements were restrained by a chin rest (see Gilchrist \& Harvey, 2000, for further details). Each trial began with participants fixating on a central circle. After 2000 msec, the circle was removed and a peripheral target (a spherical white stimulus subtending $5.2^{\circ}$ of visual angle) appeared $4.8^{\circ}$ to the left or right of fixation. In four blocks of prosaccade trials, participants were instructed to look directly at the peripheral target as quickly as possible. In four blocks of antisaccade trials, participants were instructed to move their eyes horizontally away from the target. The conditions were blocked and order of presentation was counterbalanced, with the constraint that prosaccade and antisaccade tasks alternated across the blocks. Each block consisted of 60 trials, with the target appearing equally often to the left and right of fixation. The location of the target on each trial was randomized by the computer. Of the eight experimental blocks, six comprised the prosaccade and antisaccade tasks paired with the various $n$-back conditions (i.e., 0,1 , and 2 ). The remaining two blocks comprised control trials in which participants performed only the prosaccade and antisaccade tasks.

The $n$-back tasks were a close auditory analog to those used in neuroimaging investigations of working memory (Jonides et al., 1997; Smith \& Jonides, 1997). Participants heard a series of letters presented via computer speakers. The set of items comprised all the letters of the alphabet with a few exceptions to minimize phonological confusion (i.e., $b, c, d, g, n, v$, and $z$ ). A new letter was presented every 3000 msec. The 0-back task required participants to judge whether each letter matched a target letter (e.g., $F$ ) that was specified by the experimenter. The 1-back task required participants to judge whether each letter matched the preceding item in the series, and the 2-back task required participants to judge whether each letter matched the item two back in the series. Participants made their responses by pressing the appropriately labeled keys (i.e., YES or NO) on the keyboard. Each $n$-back series comprised a sequence of 60 letters (20 hits and 40 distractors). Following a period of fixation on the central circle (i.e., $1000 \mathrm{msec}$ ), the next letter in the $n$-back sequence was presented. After a further delay of $1000 \mathrm{msec}$, the fixation circle disappeared and the peripheral target was displayed. The target remained on the screen for $1000 \mathrm{msec}$, after which time the fixation circle was displayed again, thereby signaling the start of the next trial. Prior to recording their eye 
movements, participants were familiarized with the sound of each letter and the three $n$-back tasks. Following the completion of all eight experimental blocks, participants were debriefed, thanked for their participation, and dismissed.

\section{Experiment 2}

\section{Participants and Design}

Eighteen students at the University of Bristol participated in the experiment. The experiment had a 2 (condition: no-saccade or antisaccade) $\times 3$ (concurrent task: 0-, 1-, or 2-back) repeated measures design.

\section{Procedure and Stimulus Materials}

As in Experiment 1, each trial began with participants fixating on a central circle and, after $2000 \mathrm{msec}$, the circle was removed and a peripheral target appeared. Given the relatively low error rate that was observed in Experiment 1, attempts were made to increase the difficulty of the antisaccade task in the present experiment. Specifically, the peripheral target was changed from a single white stimulus to a collection of 60 different color photographs of various objects (i.e., household objects, people, sporting scenes, food, and animals). These target stimuli were more varied and visually complex than the white circle that was used in Experiment 1 . The photographs subtended $4.9^{\circ}$ of visual angle and could appear in one of four (rather than two) locations on the screen: $4.0^{\circ}$ above, below, to the left, or to the right of the central fixation circle. In three blocks of no-saccade trials (60 trials per block), participants were instructed to continue looking in the center of the screen throughout the block. In the three blocks of antisaccade trials, participants were instructed to move their eyes away (horizontally or vertically) from the target. Each saccade task was paired once with each $n$-back condition (i.e., 0, 1, and 2). Experiment 2 did not include blocks in which there was no concurrent $n$-back task. The $n$-back tasks were identical to those used in Experiment 1. On completion of the experiment, participants were debriefed, thanked for their participation, and dismissed.

\section{Acknowledgments}

This research was supported by a National Science Foundation graduate fellowship to J.P.M.

Reprint requests should be sent to Jason P. Mitchell, Department of Psychology, William James Hall, 33 Kirkland Street, Harvard University, Cambridge, MA 02138, USA, or via e-mail: jmitchel@wjh.harvard.edu.

\section{REFERENCES}

Baddeley, A. (1986). Working memory. Oxford, UK: Oxford University Press.
Baddeley, A. (1996). Exploring the central executive. Ouarterly Journal of Experimental Psychology, 49A, 5-28.

Bjorklund, D. F., \& Harnishfeger, K. K. (1995). The evolution of inhibition mechanisms and their role in human cognition and behavior. In F. N. Dempster \& C. J. Brainerd (Eds.), Interference and inbibition in cognition (pp. 141-204). San Diego, CA: Academic Press.

Butler, K. M., Zacks, R. T., \& Henderson, J. M. (1999). Suppression of reflexive saccades in younger and older adults: Age comparisons on an antisaccade task. Memory and Cognition, 27, 584-591.

Cohen, J. D., \& Servan-Schreiber, D. (1992). Context, cortex, and dopamine: A connectionist approach to behavior and biology in schizophrenia. Psvchological Review, 99, 45-77.

Dahaene, S., \& Changeux, J. P. (1991). The Wisconsin Card Sort Test: Theoretical analysis and modeling in a neuronal network. Cerebral Cortex, 1, 62-79.

Damasio, A. R. (1994). Descartes' error: emotion, reason and the buman brain. New York: Putnam.

Doricchi, F., Perani, D., Inoccia, C., Grassi, F., Cappa, S. F., Bettinari, V., Galati, G., Pizzamigilio, F., \& Fazio, F. (1997). Neural control of fast-regular saccades and antisaccades, an investigation using positron emission tomography. Experimental Brain Research, 116, 50-62.

Everling, S., \& Fischer, B. (1998). The antisaccade: A review of basic research and clinical studies. Neuropsychologia. 36, 885-899.

Findlay, J. M. (1981). Spatial and temporal factors in the predictive generation of saccadic eye movements. Vision Research, 21, 347-354.

Freud, S. (1966). Psychopathology of everyday life (J. Strachey, Trans.). London: Ernest Benn. (Original work published in 1901).

Fukushima, J., Fukushima, K., Chiba, T., Tanaka, S., Yamashita, I., \& Kato, M. (1988). Disturbances of voluntary control of saccadic eye movements in schizophrenic patients. Biological Psychiatry, 23, 670-677.

Funahashi, S., Bruce, C. J., \& Goldman-Rakic, P. S. (1993). Dorsolateral prefrontal lesions and oculomotor delayed-response performance: Evidence for mnemonic "scotomas." Journal of Neuroscience, 13, 1479-1497.

Fuster, J. M. (1989). The prefrontal cortex: Anatomy, physiology, and neuropsychology of the frontal lobe (Rev. ed.). New York: Raven Press.

Gilchrist, I. D., \& Harvey, M. (2000). Refixation frequency and memory mechanisms in visual search. Current Biology, 10, 1209-1212.

Goldman-Rakic, P. S. (1995). Architecture of the prefrontal cortex and the central executive. In J. Grafman, K. J. Holyoak, \& F. Boller (Eds.), Structure and functions of the buman prefrontal cortex (pp. 71-83). New York: New York Academy of Sciences.

Guitton, D., Büchtel, H. A., \& Douglas, R. M. (1985). Frontal lobe lesions in man cause difficulties in suppressing reflexive glances and in generating goal-directed saccades. Experimental Brain Research, 58, 455-472.

Hallett, P. E. (1978). Primary and secondary saccades to goals defined by instructions. Vision Research, 18, 1279-1296.

Harnishfeger, K. K., \& Bjorklund, D. F. (1993). The ontogeny of inhibition mechanisms: A renewed approach to cognitive development. In M. L. Howe \& R. Pasnak (Eds.), Emerging themes in cognitive development: Vol. I. Foundations (pp. 28-49). New York: Springer Verlag.

James, W. (1890). The principles of psychology. New York: Holt.

Jonides, J., Schumacher, E. H., Smith, E. E. Lauber, E. J., Awh, E., Minoshima, S., \& Koeppe, R. A. (1997). Verbal working 
memory load affects regional brain activation as measured by PET. Journal of Cognitive Neuroscience, 9, 462-475.

Jonides, J., Smith, E. E., Marscuetz, C., Koeppe, R. A., \& ReuterLorenz, P. A. (1998). Inhibition in verbal working memory revealed by brain activation. Proceedings of the National Academv of Sciences, U.S.A., 95, 8410-8413.

Kimberg, D. Y., \& Farah, M. J. (1993). A unified account of cognitive impairments following frontal lobe damage: The role of working memory in complex, organized behavior. Iournal of Experimental Psychology. General, 122, 411-428.

Levine, D. S., \& Prueitt, P. S. (1989). Modeling some effects of frontal lobe damage: Novelty and perseveration. Neural Networks, 2, 103-116.

Lhermitte, F. (1983). 'Utilization behavior' and its relation to lesions of the frontal lobes. Brain, 106, 237-255.

Luria, A. R. (1966). Higher cortical functions in man. London: Tavistock.

Norman, D. A. (1981). Categorization of action slips. Psvchological Review, 88, 1-15.

Norman, D. A., \& Shallice, T. (1986). Attention to action: Willed and automatic control of behavior. In R. J. Davidson, G. E. Schwartz, \& D. Shapiro (Eds.), Consciousness and self-regulation: Advances in research and theory (vol. 4, pp. 1-18). New York: Plenum.

Paus, T., Kalina, M., Patockova, L., Angerová, Y., Cerná, R., Mecir, R., Bauer, J., \& Krabec, P. (1991). Medial vs. lateral frontal lobe lesions and differential impairment of central-gaze fixation maintenance in man. Brain, 114, 2051-2067.

Pierrot-Deseilligny, C., Rivaud, C., Gaymard, B., \& Agid, Y.
(1991). Cortical control of reflexive visually-guided saccades. Brain, 114, 821-824.

Reason, J. T. (1979). Actions not as planned: The price of automatisation. In D. Underwood \& R. Stevens (Eds.), Aspects of consciousness: Vol. 1. Psychological issues (pp. 6789). London: Academic Press.

Roberts, Jr., R. J., Hager, L. D., \& Heron, C. (1994). Prefrontal cognitive processes: Working memory and inhibition in the antisaccade task. Journal of Experimental Psychology. General, 123, 374-393.

Shallice, T. (1988). From neuropsychology to mental structure. New York: Cambridge University Press.

Smith, E. E., \& Jonides, J. (1997). Working memory: A view from neuroimaging. Cognitive Psvchologv, 33, 5-42.

Stuyven, E. Van der Goten, K., Vandierendonck, A., Claeys, K., \& Crevits, L. (2000). The effect of cognitive load on saccadic eye movements. Acta Psychologica, 104, 69-85.

Sweeney, J. A., Mintun, M. A., \& Kwee, S. (1996). Positron emission tomography study of voluntary saccadic eye movements and spatial working memory. Journal of Neurophysiology, 75, 454-468.

Walker, R., Husain, M., Hodgson, T. L., Harrison, J., \& Kennard, C. (1998). Saccadic eye movement and working memory deficits following damage to human prefrontal cortex. Neuropsvchologia, 36, 1141-1159.

Wegner, D. M. (1994). Ironic processes of mental control. Psychological Review, 101, 34-52.

Wegner, D. M., Ansfield, M., \& Pilloff, D. (1998). The putt and the pendulum: Ironic effects of the mental control of action. Psvchological Science, 9, 196-199. 


\section{This article has been cited by:}

1. C. Karatekin, C. Bingham, T. White. 2009. Oculomotor and Pupillometric Indices of Pro- and Antisaccade Performance in Youth-Onset Psychosis and Attention Deficit/Hyperactivity Disorder. Schizophrenia Bulletin . [CrossRef]

2. KATHERINE L. POSSIN, SIMONA M. BRAMBATI, HOWARD J. ROSEN, JULENE K. JOHNSON, JUDY PA, MICHAEL W. WEINER, BRUCE L. MILLER, JOEL H. KRAMER. 2009. Rule violation errors are associated with right lateral prefrontal cortex atrophy in neurodegenerative disease. Journal of the International Neuropsychological Society 15:03, 354. [CrossRef]

3. Fiona Michel, Mike Anderson. 2009. Using the antisaccade task to investigate the relationship between the development of inhibition and the development of intelligence. Developmental Science 12:2, 272-288. [CrossRef]

4. Stefan Van der Stigchel. 2009. The Search for Oculomotor Inhibition. Experimental Psychology (formerly "Zeitschrift für Experimentelle Psychologie") 1:-1, 1-7. [CrossRef]

5. André Vandierendonck, Maud Deschuyteneer, Ann Depoorter, Denis Drieghe. 2007. Input monitoring and response selection as components of executive control in pro-saccades and anti-saccades. Psychological Research 72:1, 1-11. [CrossRef]

6. Paolo Brambilla, Angus W MacDonald, Roberto B Sassi, Melissa K Johnson, Alan G Mallinger, Cameron S Carter, Jair C Soares. 2007. Context processing performance in bipolar disorder patients. Bipolar Disorders 9:3, 230-237. [CrossRef]

7. ÁRNI KRISTJÁNSSON. 2007. Saccade landing point selection and the competition account of pro- and antisaccade generation: The involvement of visual attention ? A review. Scandinavian Journal of Psychology 48:2, 97-113. [CrossRef]

8. Nicola Rycroft, Samuel B. Hutton, Jennifer M. Rusted. 2006. The antisaccade task as an index of sustained goal activation in working memory: modulation by nicotine. Psychopharmacology 188:4, 521-529. [CrossRef]

9. T. J. Crawford, M. Kean, R. M. Klein, J. P. Hamm. 2006. The effects of illusory line motion on incongruent saccades: implications for saccadic eye movements and visual attention. Experimental Brain Research 173:3, 498-506. [CrossRef]

10. Samuel B. Hutton, Ulrich Ettinger. 2006. The antisaccade task as a research tool in psychopathology: A critical review. Psychophysiology 43:3, 302-313. [CrossRef]

11. Gabriel S. Dichter, Odin van der Stelt, Jane Laube Boch, Aysenil Belger. 2006. Relations Among Intelligence, Executive Function, and P300 Event Related Potentials in Schizophrenia. The Journal of Nervous and Mental Disease 194:3, 179-187. [CrossRef]

12. P. M. Greenwood, Chantal Lambert, Trey Sunderland, Raja Parasuraman. 2005. Effects of Apolipoprotein E Genotype on Spatial Attention, Working Memory, and Their Interaction in Healthy, Middle-Aged Adults: Results From the National Institute of Mental Health's BIOCARD Study. Neuropsychology 19:2, 199-211. [CrossRef]

13. Naomi P. Friedman, Akira Miyake. 2004. The Relations Among Inhibition and Interference Control Functions: A Latent-Variable Analysis. Journal of Experimental Psychology: General 133:1, 101-135. [CrossRef] 